\title{
FUNCIONALIDADE DE IDOSOS COM FORÇA DE PREENSÃO MANUAL REDUZIDA ACOMPANHADOS NA ATENÇÃO PRIMÁRIA À SAÚDE
}

Reuber Lima de Sousa; UFPR; E-mail: reuber_souza@hotmail.com;

Kamila Alves Brasileiro; UFPR; E-mail: kamilabrasileiro@gmail.com;

Aline de Sousa Falcão; UFPR; E-mail: alinesousafalcao@hotmail.com;

Conceição da Silva Brito; UFPR; E-mail: enfbryto@gmail.com;

Márcia Marrocos Aristides Barbiero; E-mail: marciamarrocos@gmail.com;

Patrícia Rosa Gonçalves Leta; E-mail: patriciarg|@hotmail.com;

Maria Helena Lenardt; E-mail: curitiba.helena@gmail.com;

Susanne Elero Betiolli; E-mail: susanne.elero@yahoo.com.br.

\section{RESUM0}

Introdução: a redução da força de preensão manual (FPM) pode afetar a capacidade funcional, acarretar limitações funcionais e impactar na qualidade de vida do idoso. Objetivo: avaliar a funcionalidade de idosos com força de preensão manual reduzida na atenção primária à saúde. Métodos: estudo quantitativo transversal realizado em uma Unidade Básica de Saúde de Curitiba/ PR (Brasil), com amostra constituída por 389 idosos ( $\geq 60$ anos). Realizou-se o rastreio cognitivo previamente à coleta de dados. Os dados foram coletados por meio da aplicação de escalas de avaliação da funcionalidade como o Índice de Katz para as atividades básicas de vida diária (ABVD) e Lawton e Brody para as atividades instrumentais de vida diária (AIVD). A FPM foi mensurada pelo dinamômetro hidráulico (marca Jamar $\left.{ }^{\circledR}\right)$. Realizou-se análise estatística descritiva. O estudo foi aprovado por Comitê de Ética em Pesquisa sob n ${ }^{\circ}$ 2918847. Resultados: houve predomínio de idosos do sexo feminino $(n=255 ; 65,6 \%)$, com idade entre 60 e 69 anos $(n=186 ; 47,8 \%)$. Dos 389 idosos, 82 (21\%) apresentaram FPM reduzida, dos quais a maioria era independente para as $\operatorname{ABVD}(\mathrm{n}=72 ; 87,8 \%)$, no entanto, dependentes para uma ou mais AIVD ( $\mathrm{n}=49 ; 59,7 \%)$. Conclusão: o declínio da funcionalidade impacta principalmente nas AIVD e considera-se que a avaliação da FPM na funcionalidade dos idosos, aplicadas à prática clínica, possa prever desfechos negativos para a autonomia e independência.

Palavras-chave: Idoso fragilizado; Força da mão; Atividades cotidianas; Enfermagem geriátrica.

Agradecimentos: À Coordenação de Aperfeiçoamento de Pessoal de Nível Superior (CAPES) e ao Conselho Nacional de Desenvolvimento Científico e Tecnológico (CNPQ) pelas concessões de bolsas de Mestrado/Iniciação Científica. 